\title{
Estudios recientes de ecos polares mesosféricos de verano bajo ondas HF
}

\section{Recent studies of polar mesosphere summer echoes under HF heating waves}

\author{
*Henry O. Pinedo Nava
}

\section{RESUMEN}

La intensidad de una capa de los ecos polares mesosféricos de verano (EPMV) muestra una distribución con forma de "montaña". En este trabajo se presenta evidencia que efectos en el EPMV, debido al calentamiento artificial de electrones ionosféricos causado por el HF-heating, se manifiestan principalmente en la región interna alrededor del pico del EPMV. Evaluando sólo tal región interna conducirá a otras estimaciones de temperatura de electrones y otros estados de los procesos físicos como difusión de electrones y cargado de las partículas de polvo. En primera instancia, este descubrimiento puede servir a mejorar los modelos disponibles sobre EPMV bajo HFheating. Se discute acerca de posibles interpretaciones físicas considerando tamaño y densidad de electrones y las partículas de polvo. También se discute en términos de los principales procesos físicos: difusión de electrones y cargado eléctrico de partículas de polvo. No se ha encontrado efectos del HF-heating en los parámetros de la dinámica neutral: velocidad radial y ancho espectral. Un beneficio tecnológico del presente trabajo es que para detectar y evaluar los efectos del HF-hosting no se requieren potentes transmisiones de radar. Permitiendo usar tecnología más asequible que además permitirá realizar mediciones más continuas de la Mesosfera Polar.

Palabras clave: Calentador artificial HF de electrones, EPMV, mesosfera, radar.

\begin{abstract}
The backscatter-strength altitude-profile of a single layer of Polar Mesosphere Summer Echo (PMSE) shows a mountain-like distribution. Hereby are presented evidence that effects on the PMSE, due to the artificially modified electron temperature caused by the HF wave, are mainly manifested in the inner region around the PMSE peak. Evaluating only such inner region lead to other estimations of electron temperature and other status of physical processes like dust charging and electron diffusion. At first instance, this finding can serve to improve available models of PMSE under HF heating. Discussions are provided about possible physical interpretation considering size and densities of electrons and ice particles. It is also discussed in terms of the main physical processes: electron diffusivity and dust charging. It has not been found HF heating effects on neutral dynamic parameters: radial velocity and spectral width. A straightforward initial benefit from present work results is that detecting and evaluating heating effects do not required powerful radar transmissions. This finding supports using more affordable technology that will allow more continuous measurements of the Polar Mesosphere.
\end{abstract}

Keywords: Mesosphere, PMSE, HF heating, radar.

${ }^{1}$ Former Research Fellow at the Arctic University of Tromsø - Physics and Technology Department. Correo electrónico: henry.pinedo@uit.no 


\section{INTRODUCTION}

The polar mesosphere is a highly dynamic region where complex physical and chemical processes take place. In-situ measurements have contribute significantly on the understanding of this region, however they are complex and expensive that they are limited to a very few discrete measurements, e.g. sounding rockets. The use of ground-based instrumentation allows remote sensing of mesosphere with more affordable technology, and especially with more continuous measurements covering larger volumes as for better evaluation of its dynamics. Radar systems have contributed providing large number of multi-range and timespace spectral measurements. Havnes (2004) expanded the radar capabilities on the study of Polar Mesosphere by introducing a theory describing the role of dust particles from meteor origin on the PMSE mechanism. The experimental setup includes an optimized pulse of powerful HF waves for electron heating in the PMSE environment, while the radar measure the PMSE before, during and after the heating pulse. This technique allows the use of mesosphere as a real laboratory.

The radar technique is capable of detecting echoes from weak fluctuations in the atmospheric refractive index. This technique requires frequency coherence - i.e., that the received signal is mixed with the transmitted frequency to retain both the amplitude and phase of returned signals. Most of the signal analysis processing involves the power spectrum of the coherently demodulated echoes. Shape-based basic parameters are obtained from its power spectrum, which in turn, through well- supported theory (Balsley and Gage, 1980; Farley, 1985; Woodman 1985), allows relating them to physical parameters. It has been suspected that long-term changes in the Mesopause environment are related to anthropogenic activity (e.g. Roble and Dickinson, 1989; Thomas et al., 1989). Radar measurements of this region (PMSE) can provide a kind of "canary in a coal-mine" about such concern.

The present work reports analysis of heating effects on inner and outer regions of a single PMSE layer. It has been found that these two regions respond differently to the heating wave. Discussions are provided about the possible interpretations and its implications on the understanding of the Polar Mesosphere physics. As an introduction it is included a short review of polar mesosphere summer echoes and the HF heating effects. There are also associated technical advantages confirming the use very low power transmissions for evaluating the HF heating effects on the EISCAT VHF. This will make economically feasible continuous measurements with present facilities and future array antenna measurements.

\section{Polar mesosphere summer echoes}

Polar mesopause temperatures show extremely low levels of about 130K during summer (e.g. Von Zahn and Meyer, 1989; Lübken, 1999). This thermal condition allows ice particles formation, which grow and begin to be visible from ground as noctilucent clouds NLC. Displays of these clouds were firstly connected with volcanic eruption of Krakatoa in 1883, and the first reported observations recognized that they were unusual (Leslie, 1885). Many years have elapsed since that tectonic event, however, occurrence of these clouds remains until now.

Small dust charged particles in the polar summer mesosphere, with ice particles associated to noctilucent clouds, play a decisive role in the physical mechanism of PMSE (Havnes et al., 1996, 2001). Dust or aerosol particles are any solid particle (icy or mixed with e.g. metals) with sizes from about a nanometer and upwards. It has been confirmed by experimental and model results that presence of charged dust particles reduces the electron diffusivity and dust particle charging is due to electron an ion collisions including attachment onto their surface. Electron diffusivity and dust charging are two factors playing important roles on PMSE (Chilson et al., 2000; Havnes et al., 2003; Belova el al., 2003; Rapp and Lübken, 2000, 2003b; Havnes, 2004).

Therefore, as summarized by Rapp and Lübken (2004), mesospheric neutral air turbulence in combination with significantly reduced electron diffusivity due to the presence of heavy charged ice dust particles (radii $\sim 5-50 \mathrm{~nm}$ ) leads to the creation of structures at spatial scales significantly smaller than the inner scale of the neutral gas turbulent velocity field itself. This constitutes a theory which has been largely proved by experiment results performed with different type of instrumentation like satellites, sounding rockets, ground based observations, and results from numerical models as well. Owing to this low diffusivity on electrons, the plasma structure acquires a very long lifetime that leads to a temporal decoupling of active neutral air turbulence. It allows PMSE to be a suitable tool for monitoring the thermal and dynamical structure of the mesopause region. 


\section{PMSE overshoot effectIt}

was discovered that artificial electron heating strongly affects (mainly weakening) the polar mesosphere summer echoes when it is observed at $224 \mathrm{MHz}$ (Chilson et al., 2000), and at $933 \mathrm{MHz}$ (La Hoz et al., 2003). Based on this artificial electron heating technique, Havnes (2004) proposed a modification of that technique as for detecting charged particles in the summer mesopause, called the PMSE overshoot effect. The new approach requires an extended period of relaxation (heatingoff) to allow enough time for the PMSE to restore until its initial undisturbed level. Turn-on period is of the order of tens of second while the turn-off period is a couple of minutes. This cycle (on/off) is repeated during certain time while PMSE is present. After compile echoes datasets generally from high signal to noise ratio, these dataset cycles are epochaveraged. The corresponding result is called the overshoot characteristic curve OCC (Havnes et al., 2003), which confirmed the theoretical predictions (Havnes et al., 2003; Havnes, 2004). It has three stages: (1) PMSE echo strength is dropped almost instantaneously once the heater is switched on; (2) a recovery in the signal strength is usually shown during the heating-on period; (3) right after the heating is switched off, it takes place a rapid high strengthening of the signal (compared with the value just before heating was switched on (See bottom-plot at Figure 1).

In the first stage of the PMSE OCC, the drop in the echo strength due to heating is determined by the electron temperature increase (Havnes et al., 2004). This increase of electron temperature is argued to lead the diffusion of electrons and ions into another equilibrium configuration with a reduction of electron density gradients or spatial irregularities that produce the radar scatter (La Hoz and Havnes, 2008). In the PMSE OCC second stage, dust charging can overcome the electron diffusion process and thereby increasing the gradients in the electron irregularities via the Coulomb force (Havnes et al., 2004). Therefore, it can be a small increase of the backscatter strength in this stage. In the last PMSE OCC third stage, when the heater is turned off, the electrons recover their initial background temperature as quickly as they were heated and will also quickly adjust to equilibrium. As higher the charge number of charged dust particles that was accumulated during the artificial heating on period (dust charging), the larger electron density gradients would be induced. This electron density gradient is controlled by the gradient distribution of charged dust particles. It is the presence of charged dust particles that are responsible of the predicted and observed characteristics of the second and third stages of the OCC.

\section{EXPERIMENTAL METHOD}

Results presented in this work are from experimental campaign measurements during June and July 2013, mainly from June $17^{\text {th }}$ and July $26^{\text {th }}$.

The campaign includes multi radar wavelengths from the Mobile Rocket and Radar Observatory MORRO MST radar $\left({ }_{\text {Bragg }}=2.60 \mathrm{~m}\right)$, the European Incoherent Scatter Scientific association EISCAT VHF $\left({ }_{\text {Bragg }}=0.67 \mathrm{~m}\right)$, and UHF $\left({ }_{\text {Bragg }}=0.16 \mathrm{~m}\right)$ radars. The EISCAT HF heating facility (Rietveld et al., 2016, 1993) was used for the artificial modification of the ionospheric electron temperature. The HF heating setup was O-mode polarization at $6.77 \mathrm{MHz}$ with 601 MW of effective radiated power (ERP) using 10 transmitters on Array 1. ERP estimation assumes a perfectly reflecting ground. Although, full campaign involved multi radar measurements, in present work is presented data only from the EISCAT VHF. All the listed facilities are collocated in the EISCAT site at Ramfjordmoen in Tromsø city in Norway $\left(69.6^{\circ} \mathrm{N}\right.$, 19.2 ${ }^{\circ}$ ).

Successful measurement for this type of experimental campaign requires precise multi- radar synchronization, RF pulse setup, knowledge of the ionospheric conditions for setting the Heating frequency and polarization. Moreover, efficient and effective big data management and radar signal processing techniques for analysis of the measurements. The EISCAT radars used the MANDA program that delivers 128 pulses with different 61 phase-codes (bauds) for each pulse. All the instruments were synchronized according to this program. On June $17^{\text {th }}$ and July $26^{\text {th }}$, the HF heating cycle length was 192 and $216 \mathrm{~s}$ respectively. In both cases the heating pulse length was $48 \mathrm{~s}$. A timesynchronized measurement averaging respect to the each heating stage is required to evaluate independly them. In special to evaluate the immediate change on the PMSE due to the up/down states of the heating pulse.

The backscatter from a radar transmission is received and transduced into electric voltages by the antenna. The carrier radar frequency is extracted to keep only the PMSE signal and its Doppler information. These processed voltages are finally recorded with a sampling rate of 1.2 [us] or $180[\mathrm{~m}]$ assuming speed 
of light to $3 \mathrm{e} 8[\mathrm{~m} / \mathrm{s}]$ and round trip path for present monostatic radar configuration case. This collection of samples is called a range profile, there are as many range profiles as number of transmitted pulses, and the time step between them is known as inter-pulseperiod (IPP) with 1.5 [ms]. The decoding process, for recovering the phase coded voltages, includes only the fully decoded gates.

Depending on the physical correlation time of PMSE, the signals can be averaged in time as for improving the signal to noise ratio (SNR). The averaging time-length in voltage domain has to be properly chosen to allow including the whole available PMSE spectral information to avoid cancelling the coherence of signals. For the specific case of data used in this work, they are first averaged in voltage domain $\mathrm{N} 1=32$ times and then averaged in power domain $\mathrm{N} 2=10$ times. The final data time step is IPPxN1xN2=0.48 [s]. Averaging and decoding are linear and commutative processes, however it is more convenient to perform averaging after decoding when data size are reduced when using only the fully decoded gates. Data set at this point is a 2D array collection of range profiles, where its vertical axis represents range (altitude in present case when radar points vertical) and its horizontal axis represents time. Some graphic results show volumetric radar cross-section $\left[\mathrm{m}^{-1}\right]$ based on electron density estimations from EISCAT UHF measurements.

\section{RESULTS}

the standard procedure of the so-called overshot characteristic curve (OCC) analysis will be named in present work as the heating-effects characteristic curve (HCC). This is based on the fact that such curve has been used to evaluate all the heating effects in addition to the overshoot itself. Figure 1 summarizes the main multi-analysis results for a single PMSE layer. The black line in bottom plot shows the HCC, i.e. altitude-averaged PMSE strength measurements inside a selected altitude range defined by the horizontal sketched black dotted lines in the top Range-Time-Intensity RTI map.

The RTI map shows the estimated volumetric radar cross-section, their bottom and top-right-side black lines are the averaged values along altitude (only inside horizontal black dotted lines) and time (whole altitude profile) respectively. Red line in bottom plot is the smoothed black line, heating effects are evaluated using these lines. Blue line in top-right plot is estimated electron density from EISCAT UHF measurements.

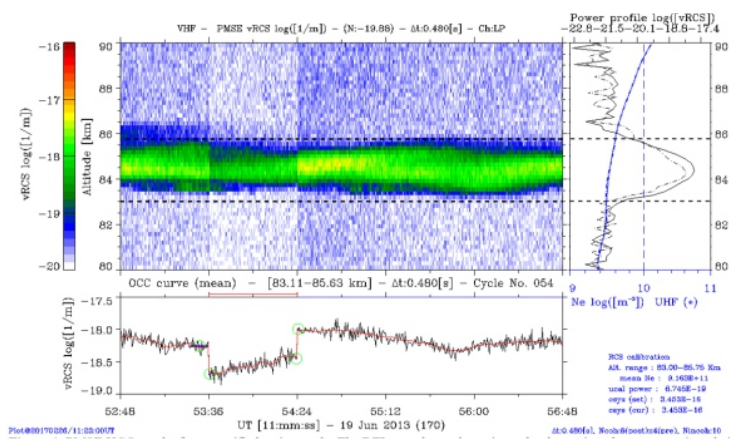

Figure 1. PMSE HCC results for a specific heating cycle. The RTI map shows the estimated volumetric radar cross-section, their bottom and top-right-side black lines are the averaged values along altitude (only inside horizontal black dotted lines) and time (whole altitude profile) respectively. Red line in bottom plot is the smoothed black line, heating effects are evaluated using these lines. Blue line in top-right plot is estimated electron density from EISCAT UHF measurements.

The RTI map shows the estimated volumetric radar cross-section, their bottom and top-right-side black lines are the averaged values along altitude (only inside horizontal black dotted lines) and time (whole altitude profile) respectively. Red line in bottom plot is the smoothed black line, heating effects are evaluated using these lines. Blue line in top-right plot is estimated electron density from EISCAT UHF measurements.

The red line shows the smoothed version of black line taking into account the edges at each heating stage start-end times. The top-right plot shows the electron density (blue) altitude profile estimated from EISCAT UHF measurements, and the PMSE timeaveraged altitude profile: black continued and dotted corresponding to heating-off and heating-on periods respectively. The intensity altitude profile of a single PMSE layer shows generally a mountain-like strength distribution from noise level at its outer borders to a peak value somewhere in its inner region. These two regions have to be classified in order to evaluate independly the heating effects. It is a matter to define a threshold or boundary value between these regions. Using as reference the minimum and maximum intensities would lead to miscalculations because of eventual very high peak values due to the random nature of PMSE. It is proposed an strategy to overcome this constraint: 1) All measurements inside the selected PMSE layer are sorted by amplitude; 2) at positions corresponding to certain percentages respect to total number of such selected samples, 
respective amplitudes are chosen as threshold values for defining region boundarises; 3) Finally, the classical HCC procedure is applied for these two regions to evaluate their independent heating effects.

\section{Inner and Outer PMSE HCC}

In this work is presented evidence that PMSE heating effects are mainly and mostly manifested in its inner region around its peak value, while the outer borders do not usually show clear signs of do not usually show clear signs of heating effects. Analysis includes only two regions: the outer and inner region of selected PMSE layer. The threshold percentages are defined for each heating cycle taking into account PMSE weakening level due to heating effects, eventual leakage effect in decoding when PMSE strength is very high, and environment conditions affecting the background noise.

Thickness of outer region behaving differently from the inner region could unveil new physical insight about the mesospheric cloud physics and its interaction with surrounding environment. More refined studies in this line is constrained by present radar range resolution. Until this improved technical capability would be available, evaluating the thickness of outer region or more inner regions remain as future work. It is remarked that main contribution of present work is reporting the identification of the main region interacting with the HF heating wave.

The Figure 2 summarizes the HCC analysis for each region inside selected PMSE layer. This figure has the same measurements shown in Figure 1, and each classified inner and outer regions of selected PMSE layer are colored with red and gold color respectively. The top RTI map show the classified inner and outer region of a single PMSE layer. The bottom time series plot are the averaged values from each classified region. The black time series was calculated by using the whole PMSE layer (i.e. including both outer and inner regions). The two vertical black lines in the bottom plot define the start and end of heating pulse. The threshold intensity levels used for selection of the two regions varies according the PMSE conditions. The main factor that defines the middle percentage level of these regions is the level of PMSE weakening just after the heating pulse. This weakening is different for each heating cycle. Results shown in Figure 2 corresponds to 1560 and $60-100 \%$ (respect to the peak value) for the outer and inner region respectively. In order to verify that this effect was not present only on July 26th, it has been performed the analysis to data from another different day.
[Top] shows RTI of both regions (gold and red). [Middle] HCC based on statistic mean for outer and inner regions (gold and red). [Bottom] Normalized HCC based on results shown at the middle plot, each case is normalized respect to average from 10 seconds previous to start of heating pulse. Black time series in bottom plot corresponds to the typical HCC result using whole selected layer. The two vertical lines in bottom plot indicate the start and end of heating pulse.
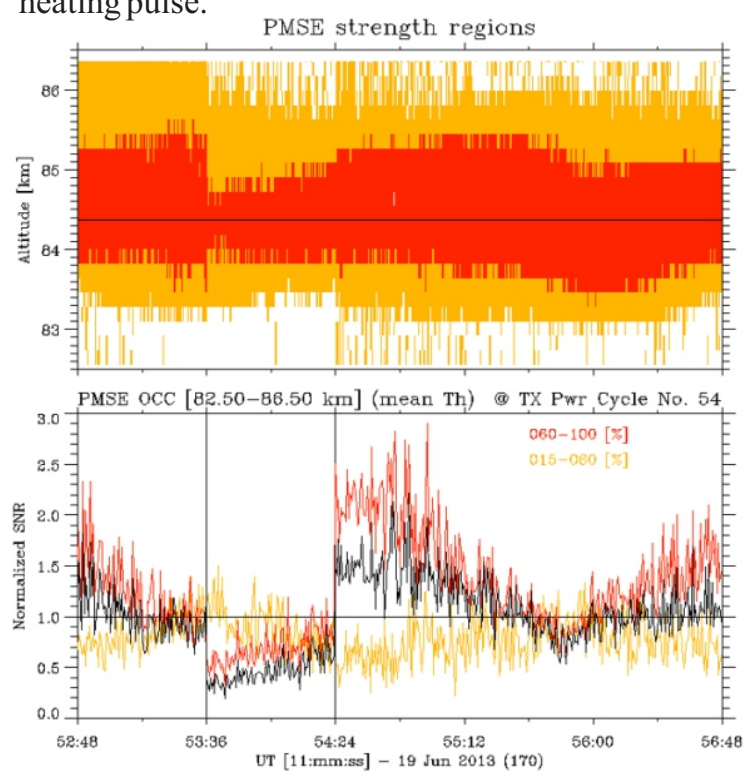

Figure 2. HCC analysis of outer and inner regions of selected PMSE layer. [Top] shows RTI of both regions (gold and red). [Middle] HCC based on statistic mean for outer and inner regions (gold and red). [Bottom] Normalized HCC based on results shown at the middle plot, each case is normalized respect to average from 10 seconds previous to start of heating pulse. Black time series in bottom plot corresponds to the typical HCC result using whole selected layer. The two vertical lines in bottom plot indicate the start and end of heating pulse.

[Top] shows RTI of both regions (gold and red). [Middle] HCC based on statistic mean for outer and inner regions (gold and red). [Bottom] Normalized HCC based on results shown at the middle plot, each case is normalized respect to average from 10 seconds previous to start of heating pulse. Black time series in bottom plot corresponds to the typical HCC result using whole selected layer. The two vertical lines in bottom plot indicate the start and end of heating pulse.

Figure 3 summarize statistical analysis over inner and 
outer PMSE region in 23 heating cycles of 37 available on June 17th 2013.

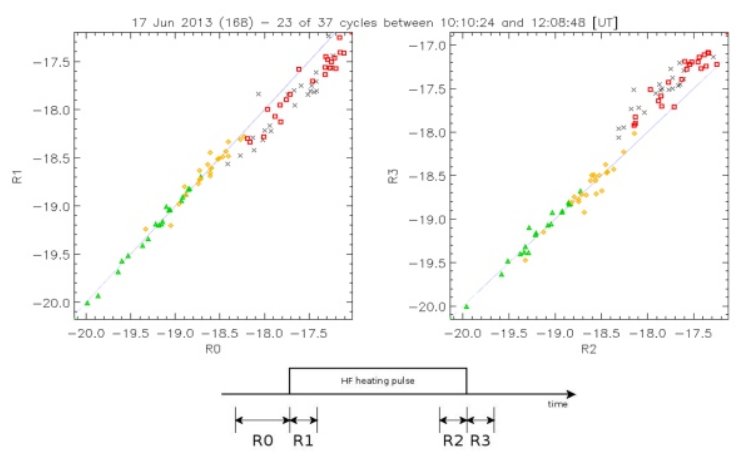

Figure 3. (Top) Statistical evaluation of the existence of different heating effects from the inner and outer regions of PMSE layer from many heating cycles, 23 of 37 available, on June 17th 2013. Left and rigth side correlograms compare R1 vs R0 and R3 vs R2 respectively for the three different regions (noise level, outer and inner, with green, gold and red color respectively) inside the selected PMSE layers. (Bottom) Sketch about time periods from where R0, $\mathrm{R} 1, \mathrm{R} 2$ and R3 parameters are estimated.

Left and right side correlograms compare R1 vs R0 and R3 vs R2 respectively for the three different regions (noise level, outer and inner, with green, gold and red color respectively) inside the selected PMSE layers. (Bottom) Sketch about time periods from where R0, R1, R2 and R3 parameters are estimated.

The criteria for choosing a particular day available from the experimental campaign is basically when the PMSE have high occurrence rate and any heating effect is clearly appreciated. The scatter plots in Figure 3 compare R1 vs. R0 (left-side) and R3 vs. R2 (right-side). These four parameters are used to evaluate HF heating effects on the PMSE. They are calculated for each individual HCC result (See bottom plot of Figure 2). R0 is the average along $10 \mathrm{~s}$ before the start of heating pulse, R1 is the average along $1 \mathrm{~s}$ after the start of heating pulse, R2 is the average along $1 \mathrm{~s}$ before the end of heating pulse, and $\mathrm{R} 3$ is the average along $1 \mathrm{~s}$ after the end of the heating pulse (See bottom diagram in Figure 3). R0 and R1 are consecutive levels, the same as R2 and R3. A scatter plot between each parameter pair will show changes between them due to the HF heating. In Figure 3, gold-diamonds, red-squares, greentriangles, correspond to outer region, inner region, and background noise respectively. Although results in Figure 3 may have some possible outliers, the overall situation is as already stated, inner regions around the peak interact more with the HF heating. This can be corroborated in Figure 3 where redsquares (inner region) are located around blackcrosses (estimations using the whole PMSE layer).

\section{PMSE spectral analysis}

In order to attempt identifying correlated effects on available parameters like radial velocity and spectral width estimated from spectral analysis. However, to evaluate independly each stage of the heating pulse a heating-pulse-time- synchronized averaging is also performed for the spectral analysis. Radar backscatter comes from free ionospheric electrons irregularities. Due to natural interaction of charged particles, electrons are linked to large sized ions. Ions in turn interact by macro collisions with large sized neutral particles following the polar mesosphere neutral dynamics. Therefore, radial velocity and spectral width estimated from radar backscatter can be used to characterize neutral dynamics of the polar mesosphere. Figure 4 shows the radial velocity for a sequence of 6 heating cycles.

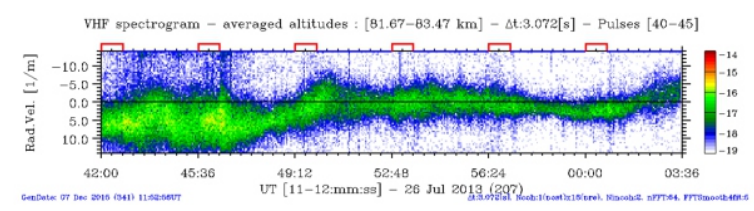

Figure 4. Spectral results of radial velocity at an specific altitude range (averaged, 81.67$83.47 \mathrm{~km})$ for a set of 6 heating cycles $(40-$ 45) on July 26th 2013 (See red color sketched pulses at top). Heating effects are not present in this physical parameter of the radial velocity.

Heating effects are not present in this physical parameter of the radial velocity.

The spectral results were calculated from raw voltages averaged inside the altitude range of 81.67 $83.47 \mathrm{~km}$. It can be appreciated that there are not evident $\mathrm{HF}$ heating effects on the radial velocity.

Figure 5 evaluates the spectral results of radial velocity in concern of heating effects during a single heating cycle. It is confirmed that there are not heating effects on the radial velocity. These spectral results were also calculated for data inside an altitude range of $81.13-83.47 \mathrm{~km}$. The PMSE was very intense during this cycle and there are a lot of "spectral noise and interference". 


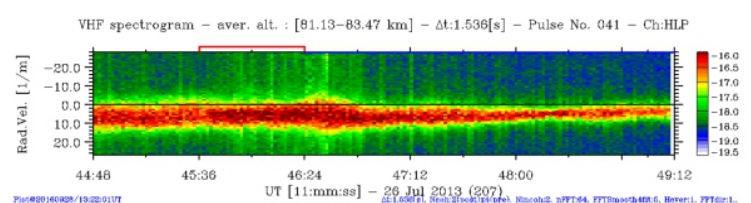

Figure 5. A more detailed view of the spectral results, radial velocity heating cycles 41 on July 26th 2013 (See red color sketched pulse at top). Here it is more clear that ther are not heating effects.

Another parameter used on defining neutral dynamics is the spectral width. Figure 6 show simultaneously the radial velocity and the spectral width results for the same period of time. These results are estimations of these two parameters for each range and time. The heating effects are not present in these two parameters

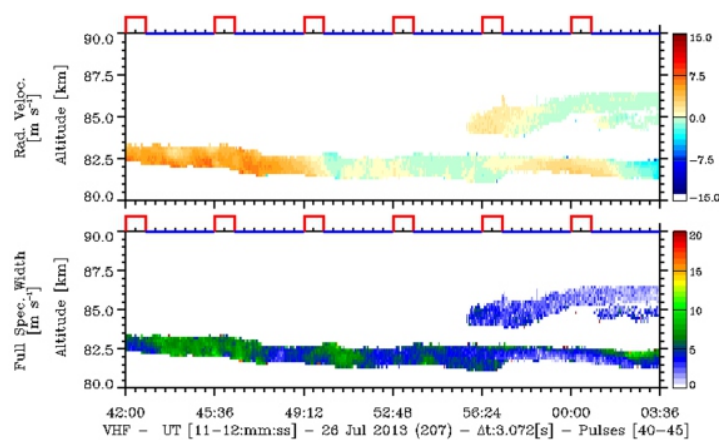

Figure 6. Radial velocity and spectral width estimated from Tromsø VHF EISCAT voltages during the period of time corresponding to heatingn cycles 40-45.

Present spectral results for radial velocity and spectral width (See Figures 4, 5 and 6), are clear confirmation that the dynamic of neutral elements is not affected by the HF heating wave. According to Figure 6, the behavior of these two parameters do not show any type of correlation with the spatial location of the classified two regions inside the PMSE layer. This is an indication that neutral dynamics may not be playing an important role on defining the previously cited inner and outer regions inside the PMSE layer. Or if exist any role, it is not manifested on the neutral spectra. The individual spectra calculated for specific time and range (altitude) are shown in Figure 7.
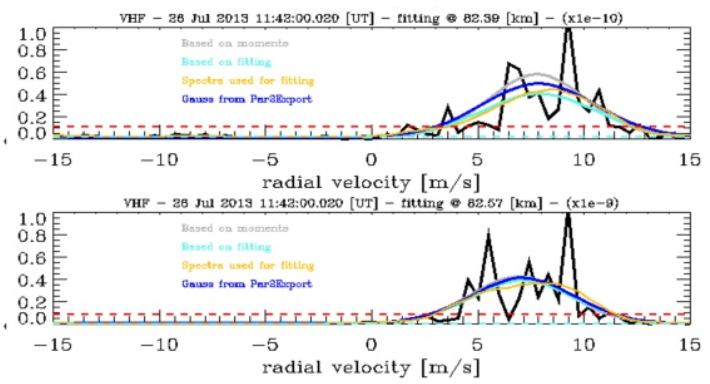

Figure 7. Spectral results at an specific time (11:42:00 UT) and altitudes ( 82.57 and $82.39 \mathrm{~km}$, bottom and top plots respectively) showing the performed Gaussian fitting results from which are estimated the radial velocity and spectral width. Note that PMSE spectra is not a smooth Gaussian but has many peaks.

Note that PMSE spectra is not a smooth Gaussian but has many peaks 2 raw voltages time-samples are collected at an specific altitude and the power spectra is calculated from them. The collection of samples can be previously integrated (or averaged) in the time domain (voltage) or frequency domain (power spectra) in order to improve the signal to noise ratio. The total frequency bandwidth will be affected by the number of time-domain integrations. The top and bottom plot in Figure 7 are for ranges separated by one gate.

Many processes in nature and specifically in the ionosphere follow the Gaussian or Normal distribution. Defining a more suited function for PMSE is not part of present work, but a Gaussian function is used as first approximation in the fitting process. The first estimation as input for the Gaussian fitting process comes from the statistical moment estimation of the same data. For any mathematical function, the presence of many peaks on the PMSE spectra represent a high challenge on the fitting process. The implemented strategy on finding the best fit, is averaging of the spectra with modelled spectra iteratively until the fitting result matches the smoothed spectra.

\section{Ionospheric electron density \& PMSE}

Evaluating the electron density has an important constraint related to the short correlations time of the irregularities from which electron density can be estimated. That requires long time integrations, and the final time resolution use to be longer than the time scales of a heating cycle and of the PMSE. Therefore, electron density measurements required to evaluate the reported differences of heating effects from outer and inner regions will require more sophisticated techniques or in-situ measurements with rockets. Figure 8 shows the RTI map, where intensity corresponds to the electron density.

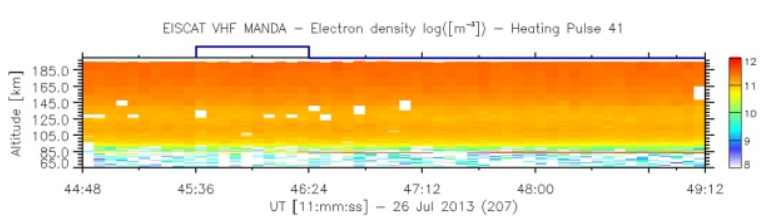

Figure 8. Electron density RT map estimated from EISCAT VHF measurements on July 26th durint the heating cycle 41 . 
These electron density have been calibrated and estimated by EISCAT with standard routines from GUISDAP (Lehtinen and Huuskonen, 1996). Inspecting the electron density background is useful to discriminate situations when there are particle precipitation events or any other sudden event caused by the sun-earth interaction. In present cases, there was not any ionospheric electron density disturbance.

\section{Low-power Tx to detect heating effects}

Present analysis is based on the fact that the received power is proportional to the transmitted power. Present PMSE SNR backscatter measurements correspond to $1.5 \mathrm{MW}$ VHF power transmissions. Backscatter measurements from different transmission powers can be estimated from real measurements from a higher power transmission by setting a respective threshold level for each of them. The simulated power levels have certain number of times less than the original high power transmission of 1.5 MW, please see Table 1 for details.

Table 1. Details of simulated transmitter powers.

\begin{tabular}{crc}
\hline $\begin{array}{c}\text { Number } \\
\text { times }\end{array}$ & $\begin{array}{c}\text { Estimated } \\
\text { Power }\end{array}[\mathbf{k W}]$ & $\begin{array}{c}\text { Color curve in } \\
\text { Figures }\end{array}$ \\
\hline 15.0 & 100.00 & Green \\
100.0 & 15.00 & Blue \\
333.3 & 4.50 & Gold \\
1000.0 & 1.50 & Red \\
\hline 2000.0 & 0.75 & Orange \\
\hline
\end{tabular}

The bottom plots in Figure 1 shows verifications that the low transmission power measurements will allow still having a clear PMSE OCC. Those curves were obtained from the standard PMSE OCC analysis using the remaining signals above the respective strength threshold levels. The conclusion from this analysis is that in order to allow more PMSE occurrence that also can provide fairly clear OCC pattern, then at least will be required a $15 \mathrm{~kW}$ transmitter.
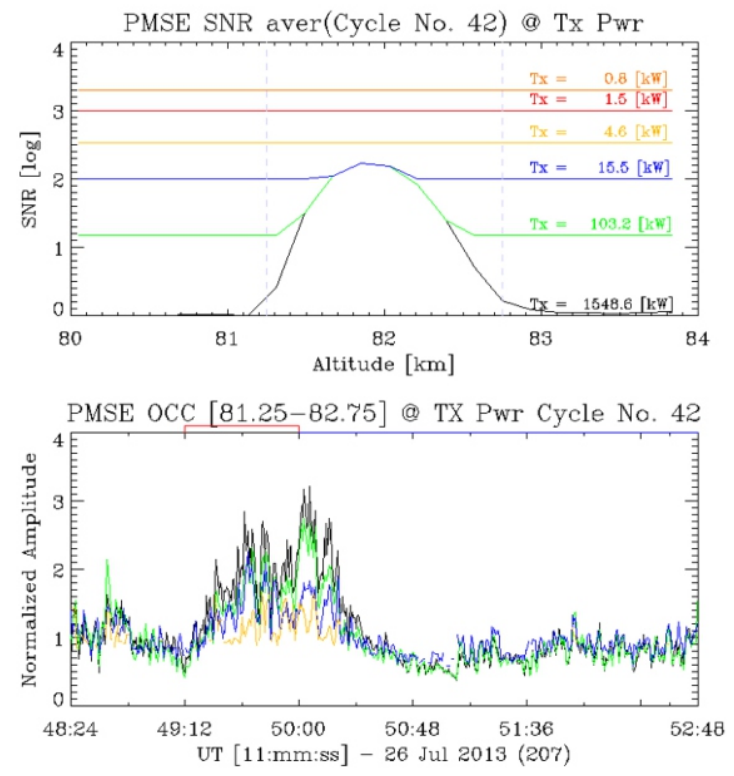

Figure 9. (Top) PMSE SNR averaged for one heating cycle and simulated profiles for different transmitted powers

Colors represent different transmission powers. Black is for the original measurements using approximately $1.5 \mathrm{MW}$, the others are for certain number of times less than that: green is for $15(\sim 100$ $\mathrm{kW})$, blue is for $100(\sim 15 \mathrm{~kW})$, gold is for $333.3(\sim 4.5$ $\mathrm{kW})$, red is for $1000(\sim 1.5 \mathrm{~kW})$, and orange is for $2000(\sim 0.75 \mathrm{~kW})$. Two dashed vertical lines indicate the altitude range that was used for PMSE OCC analysis. (Bottom) PMSE OCC evaluated between specified altitude range and for each of the simulated transmission modes, the heating cycle is sketched at the top, in red the heating-On and in blue the heatingOff.

\section{DISCUSSIONS}

The fact that outer region of PMSE layer does not show heating effects could not necessarily mean that this region does not interact with the HF heating. For instance, the effects could not be detected by radar sensitivity. Although it is a common case that whole layer change due the heating pulse, and that PMSE strength is clearly higher than noise level even at the outer region. Whether detectable or not, the main point is that outer region does not show heating effects. The PMSE weakening is smaller and the overshoot is larger when averaging only the region showing heating effects, i.e. around the peak intensity of the PMSE layer. These differences on the level of weakening and overshoot may help on refining the available models of PMSE under HF heating. 
Right after the start of heating pulse (Figure 2), the outer region (gold color) shows an apparent increase. This situation occurs when part of the higher values from the inner region gets into the outer region due to not proper threshold level setup. Dust charging may be in equilibrium with electron diffusion in the outer region of a PMSE layer, where not heating effects are reported in present work. Senior et al. (2014) concluded that dust charging can even overcome electron diffusion with certain large size and low density of ice particle. Due to gravity, it has been measured and reported in the literature that larger particles are located in the bottom of the PMSE regions. The outer top region may have other source of large charged particle from ablated material of meteor starting more frequent and intense collision with atmosphere. Further analysis and measurements are required. An initial analysis was done evaluating independently top and bottom outer region, however detailed evaluation and discussions are required be part of next work.

The present work results require also confident high altitude-resolution of electron density to evaluate its gradients and presence of the so-called "byte-outs". Present radar facilities do not have the sensitivity to properly measure the low electron densities below 90 $\mathrm{km}$. It is also required electron density estimations down to at least $60 \mathrm{~km}$ of altitude in order to evaluate the HF heating energy reaching the PMSE environment based on its estimated absorption down under. Estimations of heating energy and electron density can be used for estimating the electron temperature in the PMSE Pinedo et al. (2014) proposed a method to estimate the electron temperature from the $\mathrm{Te} / \mathrm{Ti}$, however this method relies on quiet ionospheric conditions. On the other hand, present electron density estimations have long time-resolution that do not allow a proper and synchronized evaluations of heating effects based on its pulse time-length.

The peak nature of PMSE spectra (Figure 7) may indicate the presence of diverse cloud structures or PMSEs structures with different physical characteristics each one. If so, the heating effect may affect differently to each of them. Then, it would complicate the analysis and interpretation when using a monostatic radar. Therefore, radar systems with array antennas with multiple receivers would allow using interferometric and radar imaging techniques to attempt evaluating these structures independly between them. With present and the proposed array antenna radar systems, it is required to account the beam pattern. This because, the PMSE backscatter comes basically from discrete clouds. Even from a single PMSE structure or "cloud" there may exists sub- structures as can be implied by the peaks on spectral estimations. Havnes et al. (2015) and Senior et al. (2014) have pointed out this aspect on PMSE measurements. Although, the implications may be important at $50 \mathrm{MHz}$ radars with larger beamwidths, present EISCAT VHF radar can cover a horizontal region of $1 \times 2.5 \mathrm{~km}$ with a beamwidth of approx. $0.6 \times 1.7$ degrees.

Neutral dynamics estimated parameters from present measurements, do not show heating effects according to spectral results. Although preliminary nonexhaustive spectral results presented here do not have beamwidth correction, the heating effects should manifested anyway because corrections are usually a scalar factor.

Based on results of present work, most recently it has been performed experimental campaign confirming that heating effects can be detected by low power radar transmissions, which will allow the use of affordable solid-state transmitters. New possibilities and measurements are opened like more continuous measurements and a spatially distributed array of antennas (Pinedo et al., 2016).

\section{CONCLUSIONS}

From the measurements and analysis performed in this work, it is mainly the inner region responsible for the HF heating effects in a PMSE layer. Analyzing only the region showing heating effects has led to differences on the heating effects parameters (The $\mathrm{R}$ 's). These new values have associated other electron temperature and other status of physical processes like dust charging and electron diffusion. At first instance, this finding can serve to improve available models of PMSE under HF heating. It is also clear evidence that the physical components and processes do not have a uniform spatial distribution inside a PMSE layer, which may contribute to the understanding of PMSE physics. On the other hand, the inner region of a PMSE layer is the most intense, it has been confirmed by another most recent experimental campaign (by author, to be reported) that PMSE HF heating effects can be measured by low power radar systems that can be able to detect this region. Neutral dynamics parameters like radial velocity and spectral width do not show heating effects. Although this may have been expected because the characteristics of HF heating pulse, present work confirm it with measurements. 


\section{ACKNOWLEDGMENTS}

This is a short review of most recent research activities, the experimental campaign measurements were performed as part of $\mathrm{PhD}$ program of author at The Artic University of Norway under supervision of C. La Hoz and O. Havnes and in collaboration with Mike Kosch and Andrew Senior from University of Lancaster (UK). Author wants to thank the EISCAT staff at Tromsø EISCAT site for their support during experimental campaigns, in special to Mike Rietveld, who also support with enthusiasm the author initiatives on improving new measurements. EISCAT is an international association supported by the Research Organizations in China (CRIRP), Finland (SA), Germany (DFG), Japan (NIPR and STEL), Norway (NFR), Sweden (VR), and the United Kingdom (NERC).

\section{REFERENCIAS}

Balsley, B. B., \& Gage, K. S. (1980). The MST radar technique: Potential for middle atmospheric studies, Pure and Applied Geophysics, $118(1), 452-493$. D o i : $10.1007 / \mathrm{BF} 01586464$.

Belova, E., Chilson, P. B., Kirkwood, S., \& Rietveld, M. T. (2003). The response time of PMSE to ionospheric heating. Journal of Geophysical Research: Atmospheres, $108(\mathrm{D} 8), \quad 8446, \quad \mathrm{~d}$ o i : 10.1029/2002JD002385.

Chilson, P. B., Belova, E., Rietveld, M. T., Kirkwood, S., \& Hoppe, U. P. (2000). First artificially induced modulation of PMSE using the EISCAT heating facility. Geophysical research letters, 27(23), 38013804.

Farley, D. T. (1985). On-line data processing techniques for MST radars. Radio Sci., 20 ( 6 ), $1177-1184$. d o i : 10.1029/RS020i006p01177.

Havnes, O., Pinedo, H., La Hoz, C., Senior, A., Hartquist, T. W., Rietveld, M. T., \& Kosch, M. J. (2015). A comparison of overshoot modelling with observations of polar mesospheric summer echoes at radar frequencies of 56 and $224 \mathrm{MHz}$. Ann.
Geophys, 33, 737-747. doi: 10.5194/angeo33-737-2015.

Havnes, O. (2004). Polar Mesospheric Summer Echoes (PMSE) overshoot effect due to cycling of artificial electron heating. Journal of Geophysical Research: Space $P h y s i c s, 109$ ( A 2). d o i : 10.1029/2003JA010159.

Havnes, O., Brattli, A., Aslaksen, T., Singer, W., Latteck, R., Blix, T., Thrane, E., \& Trøim, J. (2001). First common volume observations of layered plasma structures and polar mesospheric summer echoes by rocket and radar. Geophys. Res. Lett., 28, 1419-1422.

Havnes, O., La Hoz, C., Næsheim, L. I., \& Rietveld, M. T. (2003). First observations of the PMSE overshoot effect and its use for investigating the conditions in the summer mesosphere. Geophysical research letters, 30(23), 2229. doi: 10.1029/2003GL018429.

Havnes, O., Trøim, J., Blix, T., Mortensen, W., Næsheim, L. I., Thrane, E., \& Tønnesen, T. (1996). First detection of charged dust particles in the Earth's mesosphere. $J$. Geophys. Res., 101(10), 839-10,847.

La Hoz, C., \& Havnes, O. (2008). Artificial modification of polar mesospheric winter echoes with an RF heater: Do charged dust particles play an active role? Journal of Geophysical Research: Atmospheres, 113 ( D 19 ), 205 . doi:10.1029/2008JD010460.

La Hoz, C., Næsheim, L. I., Havnes, O., \& Rietveld, M. T. (2003). First observation of the artificial electron heating induced reduction of the PMSE strength at $933 \mathrm{MHz}$. In Proceedings of the EISCAT Workshop, Menlo Park, USA, August (pp. 14-19).

Leslie, R. C. (1885). Sky Glows. Nature, 32, 245 245. doi:10.1038/032245a0.

Lübken, F. J. (1999). Thermal structure of the Arctic summer mesosphere. J. Geophys. Res., $104(\mathrm{D} 8)$ ). $9135-9149$, doi:10.1029/1999JD900076. 
Lehtinen, M. S., \& Huuskonen, A. (1996). General incoherent scatter analysis and GUISDAP. Journal of Atmospheric and Terrestrial Physics, 58(1), 435-452 10.1016/00219169(95)00047-X.

Pinedo, H., Rietveld, M., Jacobsen, R., La Hoz, C., \& Havnes, O. (2016). Improved EISCAT VHF observations with dual beam for PMSE studies, EISCAT peer-review. Program for experimental campaign, 2016-I.

Pinedo, H., La Hoz, C., Havnes, O., \& Rietveld, M. (2014). Electron-ion temperature ratio estimations in the summer polar mesosphere when subject to HF radio wave heating. J. Atmos. Sol. Terr. Phys., 118, 106-112. doi:10.1016/j.jastp.2013.12.016.

Rapp, M., \& Lübken, F. J. (2004). Polar mesosphere summer echoes (PMSE): Review of observations and current understanding. Atmos. Chem. Phys., 4, 2601-2633.

Rapp, M., Lübken, F. J., \& Blix, T. A. (2003), Small scale density variations of electrons and charged particles in the vicinity of polar mesospheric summer echoes. Atmos. Chem. Phys., 3, 1399-1407.

Rapp, M., \& Lübken, F. J. (2000). Electron temperature control of PMSE. Geophysical research letters, 27(20), 3285-3288.

Rietveld, M. T., Kohl, H., Kopka, H., \& Stubbe, P. (1993). Introduction to ionospheric heating at Tromsø-I. Experimental overview. Journal of atmospheric and terrestrial physics, 55(4-5), 577-599.

Rietveld, M. T., Senior, A., Markkanen, J., \& Westman, A. (2016). New capabilities of the upgraded EISCAT high-power HF facility. Radio Science, 51(9), 1533-1546.

Roble, R. G., \& Dickinson, R. E. (1989). How will changes in carbon dioxide and methane modify the mean structure of the mesosphere and thermosphere? Geophysical Research Letters, 16(12), 1441-1444.

Senior, A., Mahmoudian, A., Pinedo, H., La Hoz, C.,
Rietveld, M. T., Scales, W. A., \& Kosch, M. J. (2014). First modulation of high-frequency polar mesospheric summer echoes by radio heating of the ionosphere. Geophysical Research Letters, 41(15), 5347-5353. doi 10.1002/2014GL060703, 2014.

Thomas, G. E., Olivero, J. J., Jensen, E. J., Schroeder, W., \& Toon, O. B. (1989). Relation between increasing methane and the presence of ice clouds at the mesopause. Nature, $338(6215), 490-492$.

Zahn, U., \& Meyer, W. (1989). Mesopause temperatures in polar summer. Journal of Geophysical Research: Atmospheres, 94(D12), 14647-14651.

Woodman, R. F. (1985). Spectral moment estimation in MST radars. Radio Science, 20(6), 1185 1195. doi 10.1029/RS020i006p01185. 